DOI 10.5937/halo27-29815

UDC: $347.56: 614.25$

Marković V. Stručna greška. Halo 194. 2021; 27(1):29-35.

Rad primljen: 10.12 .2020 .

Prihvaćen: $\quad 05.04 .2021$.

\section{Korespodencija:}

Velisav Marković

Fakultet zdravstvenih i

poslovnih

Studija, Univerzitet

SINGIDUNUM

Železnička 5, 14000 Valjevo,

Srbija

Tel: +381 14292610

E-mail:

vmarkovic@singidunum.ac.rs
PREGLEDNI RAD

\section{GRAĐANSKOPRAVNA ODGOVORNOST LEKARA ZBOG STRUČNE (LEKARSKE) GREŠKE}

\author{
Velisav MARKOVIĆ
}

Fakultet zdravstvenih i poslovnih studija iz Valjeva, Univerziteta SINGIDUNUM, Beograd, Srbija

\begin{abstract}
SAŽETAK
Građanskopravna odgovornost zdravstvenih radnika, i zdravstvenih ustanova spada u najznačajnije probleme zdravstvenog i medicinskog prava. Uvek su otvorena pitanja stvarnih osnova odgovornosti: lekarske greške, obaveštenja pacijenta i krivice u organizaciji rada. Radi otklanjanja nedoumica u praksi, autor predstavlja šta se smatra pojmom stručne (lekarske) greške, opšte uslove odgovornosti lekara (krivicu lekara, štetu za pacijenta i uzročnoposledičnu vezu između lekarske greške i štete), kao i na kome leži teret dokazivanja u eventualnom sudskom postupku.
\end{abstract}

Ključne reči: stručna greška, lekarska greška, građanska odgovornost, zdravstveni radnik

\section{UVOD}

Počev od druge polovine dvadesetog veka, pitanje građanskopravne odgovornosti lekara je stalno u centru pažnje kako pravnika, tako i medicinske struke. Pod uticajem onoga što se zbiva u praksi, težište interesovanja je pomereno sa krivične, na građansku odgovornost. Tu su stalno otvorena i aktuelna pitanja, koja se tiču stvarnih osnova odgovornosti: lekarske greške, obaveštenja pacijenta i krivice u organizaciji rada [1].

Građanskopravna odgovornost zdravstvenih radnika je jedan od najstarijih primera profesionalne odgovornosti [2,3]. Do profesionalne građanskopravne odgovornosti, dolazi zbog povrede zakonskih, ili ugovornih obaveza pripadnika slobodnih profesija, u toku pružanja profesionalnih usluga njihovim korisnicima. Nosioci slobodnih profesija, stupaju u odnose sa suptilnim partnerima (pacijentima, klijentima, strankama) kojima je, zbog neposedovanja odgovarajućih stručnih znanja ili veština, potreban savet, rešenje problema, pomoć ili neka druga profesionalna usluga. Obzirom na to, nosioci slobodnih profesija, kao profesionalci, pružaju svoje usluge koristeći svoje znanje, veštinu i povećanu pažnju, koja se upravo i naziva profesionalnom ili pažnjom dobrog stručnjaka $[4,5]$.

Obzirom na to, da je osnovna podela odgovornosti za štetu podela na neugovornu (deliktnu) i ugovornu odgovornost, postavlja se pitanje kakva je pravna priroda građanskopravne odgovornosti lekara, tj. pitanje da li se ona odvija prema pravilima ugovorne ili neugovorne odgovornosti? Ugovorna priroda odgovornosti lekara uopšte nije sporna, jer se medicinske usluge u najvećem broju slučajeva pružaju na osnovu neformalnog ugovora, koji se između lekara i pacijenata obično zaključuje konkludentnim radnjama (konkludentne radnje nisu neposredna izjava volje, ali se može posredno, sa sigurnošću, s obzirom na okolnosti, izvesti zaključak da lice njima izražava volju.) Jedino kod hitnih medicinskih intervencija, kad lekar pruža pomoć licu koje se nalazi u besvesnom stanju, ili u stanju teškog šoka, ne može biti reči o odnosu koji se zasniva ugovorom. U tom slučaju lekar istupa u svojstvu nezvanog vršioca tuđih poslova, uz uslov da je preduzeta medicinska radnja objektivno u interesu pacijenta, i da odgovara njegovoj stvarnoj ili pretpostavljenoj volji. Nema ugovornog odnosa sa pacijentom ni kad lekar obavlja njegov pregled u svojstvu sudskog veštaka [2,7]. Međutim, povredom ugovorne obaveze, lekar istovremeno čini i povredu zakonske obaveze (čuvanje dobara kao što su: pravo na život, pravo na zdravlje, telesni integritet...). Sudska praksa je redovno na odštetne zahteve prema lekarima, primenjivala pravila neugovorne odgovornosti.

$\mathrm{Na}$ polju tereta dokazivanja krivice dužnika, kod ugovorne odgovornosti krivica dužnika se ne dokazuje, već se pretpostavlja. Na tuženom, jeste teret da dokaže da nije kriv, zbog neizvršenja odnosno povrede ugovorne obaveze [8].

Građanskopravna odgovornost lekar predstavlja, u stvari, jednu oblast u okviru koje se presecaju pravila ugovorne i neugovorne odgovornosti [9].

Zakon o obligacionim odnosima, ne sadrži posebne odredbe o profesionalnoj odgovornosti. Jedina njegova odredba koja u tom pogledu predstavlja izuzetak, je pravilo koje propisuje stepen pažnje dobrog stručnjaka. Prema odredbi iz čl. 18. st. 2 Zakona o obligacionim odnosima, strane u obligacionom odnosu dužne su da u izvršavanju obaveza iz svoje profesionalne delatnosti postupaju s "povećanom pažnjom, prema pravilima struke i običajima (pažnja dobrog stručnjaka)". Zakonom o pravima pacijenata propisano je, da pacijent koji zbog stručne greške zadravstvenog radnika, odnosno zdravstvenog saradnika, u ostvarivanju zdravstvene zaštite pretrpi štetu na svom telu, ili se stručnom greškom prouzrokuje pogoršanje njegovog zdravstvenog stanja, ima pravo na naknadu štete prema opštim pravilima odgovornosti za štetu. Pravo na naknadu štete ne može se unapred isključiti ili ograničiti [10]. 
Građanska odgovornost lekara, kao i krivična, moguća je iz dva osnovna razloga: zbog nepropisnog lečenja, i zbog izostalog ili nepropisnog obaveštenja pacijenta o određenim činjenicama [1].

\section{Pojam stručne (lekarske) greške}

Pod stručnom greškom, u smislu Zakona o zdravstvenoj zaštiti, podrazumeva se nesavesno obavljanje zdravstvene delatnosti, u vidu zanemarivanja profesionalnih dužnosti u pružanju zdravstvene zaštite, nepažnje ili propuštanja, ${ }^{1}$ odnosno nepridržavanja utvrđenih pravila struke i profesionalnih veština u pružanju zdravstvene zaštite, koje dovodi do povrede, oštećenja, pogoršanja zdravlja ili gubitka delova tela pacijenta [11].

Odgovornost za stručnu grešku utvrđuje se u disciplinskom postupku pred nadležnim organom komore, $\mathrm{u}$ postupku redovne $\mathrm{i}$ vanredne provere kvaliteta stručnog rada, odnosno u drugim postupcima utvrđenim zakonom [12]. Zakonodavac u Zakonu o zdravstvenoj zaštiti koristi izraz „stručna greška”, dok je u praksi, posebno sudova, uobičajen termin ,lekarska greška".

Zanimljivo je da je Upravni odbor Komore medicinskih sestara i zdravstvenih tehničara Srbije 2015. godine doneo Pravilnik o pružanju pomoći članovima Komore u slučaju učinjene stručne greške [13]. Pod stručnom (medicinskom) greškom u smislu ovog Pravilnika, podrazumeva se propust $u$ profesionalnom radu nastao kada medicinska sestra ili zdravstveni tehničar, pri pružanju medicinske pomoći primeni očigledno nepodobno sredstvo ili metodu nege, ili ne primeni odgovarajuće preve-ntivno medicinske ili druge mere, ili uopšte, nesavesno postupa u svom radu. Sredstvo ili način su nepodobni, kada ne odgovaraju zahtevima struke $u$ datoj situaciji, a kada je ta nepodobnost toliko očigledna i pogrešna i kada je odstupila od ustaljenih i doktrinarnih principa savremene medicine, pa se ponašanje medicinske sestre ili zdravstvenog tehničara može okarakterisati kao namerna ili nenamerna medicinska greška, pod uslovom da je kod pacijenta uzrokovala pogoršanje zdravstvenog stanja, izazvala invaliditet ili smrtni ishod [13]. Pacijent koji zbog stručne (medicinske) greške člana Komore, $\mathrm{u}$ ostvarivanju zdravstvene zaštite pretrpi štetu na svom telu, ili mu se stručnom greškom prouzrokuje pogoršanje zdravstvenog stanja, ima pravo na naknadu štete prema opštim pravilima odgovornosti za štetu [13].

Kada su u pitanju sudovi, novija sudska praksa pod lekarskom greškom podrazumeva "svaku meru lekara, koja nije u skladu sa dobrom lekarskom praksom,
standardom".

Lekari i pravnici, posebno insistiraju na razlici između stručne lekarske greške i tzv. nesrećnih slučajeva u medicini. Pod ovim drugim, podrazumevaju sve nepovoljne ishode lečenja koji nisu izazvani greškom lekara, nego slučajnostima ili nepovoljnim sticajem okolnosti koje, na temelju saznanja medicinske nauke, nije bilo moguće predvideti. ${ }^{3}$

Lekarske greške se, po svojoj prirodi, mogu razvrstati na: greške u lečenju (medicinskom tretmanu); greške u obaveštavanju pacijenta; greške u vođenju medicinske dokumentacije; greške $u$ organizaciji rada i vršenju nadzora; greške u upotrebi medicinskih sprava i aparata [14].

Sadržinu pojma lekarske (stručne) greške po prof. Radišiću čini: a) negativno odstupanje od medicinskog standarda; b) medicinski standard i dužna ili potrebna pažnja; v) utvrđivanje medicinskog standarda u postupku pred sudom.

Osnovno značenje pojma lekarske greške či-ni postupanje lekara protivno pravilima vlastite struke (contra legem artis). Reč je o prenebregava-nju pravila koja čine medicinski standard. Njega lekari definišu na sledeći način: "Standard u medicini predstavlja, svagdašnje stanje saznanja prirodnih nauka i lekarskog iskustva, koje je potrebno za postizanje cilja medicinskog tretmana i koje se potvrdilo u praksi". Za svaku zasebnu vrstu lečenja, postoji i zaseban medicinski standard. Zbog ograničene mogućnosti da se do njih dođe, postojeća medicinska znanja nisu uvek sigurna, nego se svode na čistu verovatnoću. Ali postupanje lekara, i u oblasti nesigurnih znanja, vezano je za standard [1].

Za razliku od standarda industrijskih proizvoda, medicinski standard ne obavezuje lekare na bezuslovno poštovanje, jer bi to bilo nespojivo sa načelom slobode izbora metoda terapije. Ta sloboda ne znači privilegiju lekara, nego pravo u interesu drugoga, tj. pacijenta. Odstupanje od standarda, nema karakter greške, u slučaju kad lekar smatra, da stanje bolesti pacijenta to iziskuje. Slepo pridržavanje medicinskog standarda, može čak predstavljati lekarsku grešku. Odlučujuća je medi-cinska uverljivost razloga, zbog kojih se od standarda odstupa [1].

Lekar je dužan da se pridržava važećih pravila medicinske struke, i da pri tom postupa pažljivo. Tu je od presudnog značaja pitanje, koju meru pažnje i stručnosti lekar mora da pokaže. U tom pogledu valja praviti razliku između građanskog i krivičnog prava. U krivičnom pravu stepen dužne pažnje lekara određuje se, i prema objektivnom i prema subjektivnom merilu.

\footnotetext{
${ }^{2}$ Iz presude Apelacionog suda u Beogradu Gž. 6861/13 od 15.05.2014 i presude Prvog osnovnog suda u Beogradu, P. 10786/10 od 24.03.2013. godine.

3 "Od lekara se ne traži da odgovara za neuspeh intervencije, s obzirom da su komplikacije uvek moguce i da ishod lečenja nije uvek moguće predvideti, ali u lečenju ili prilikom medicinske intervencije lekar mora da postupa sa brižljivošću koju nalažu pravila struke“, iz presude Apelacionog suda u Beogradu, Gž. 6515/2010 od 20.12.2011.
}

\footnotetext{
godine.

1“"U konkrenom slučaju tužena nije dokazala da je zakazala kontrolne preglede, što predstavlja njen propust $u$ postoperativnoj nezi tužilje $i$ doprinos u nastanku štete - duševnih bolova zbog naruženosti koj opravdavaju dosuđivanje novčane naknade“, iz presude Vrhovnog kasacionog suda, Rev 881/2017 od 18.05.2017. godine.
} 
Od lekara se, naime, očekuje da pokaže pažnju koja je objektivno potrebna i subjektivno moguća. Međutim, u građanskom pravu važi, načelno, objektivno merilo za pažnju [1]. Osnovna razlika između građanske i krivične odgovornosti jeste, u standardu dužne pažnje, koje lekar treba da se pridržava, jer bi u suprotnom usledila odgovornost. Krivična odgovornost sledi samo za grubu nepažnju, dok se kod odštetne odgovara i za običnu nepažnju [15]. Vodiči dobre kliničke prakse i protokoli, predstavljaju pravila medicinske struke vezane za različite oblasti medicine, i pojedine bolesti ili stanja pacijenta. Ustanovljeni su kao putokaz lekarima i medicinskim ustanovama, kroz redosled radnji i metoda koje treba preduzeti, i primeniti prilikom zbrinjavanja pacijenta sa određenim zdravstvenim problemom. Vodiči dobre kliničke prakse, donose se na nivou čitave zemlje, a protokoli na nivou pojedinih zdravstvenih ustanova. Strogo gledano, vodiči dobre prakse i protokoli ne mogu predstavljati izvor medicinskog prava, jer ih kao takve Ustav ne poznaje. Faktički, kao i sudska praksa, oni to jesu i predstavljaju tzv. meko pravo (soft law). Od izuzetnog su značaja prilikom procene postojanja lekarske stručne greške, jer se smatra da vodiči predstavljaju medicinski standard [16].

Utvrđivanje medicinskog standarda, vrši se u odnosu na vreme kada je medicinska mera preduzeta, ili propuštena. Sud procenjuje, kako bi postupao savestan i iskusan lekar iste struke, $\mathrm{u}$ istoj situaciji, $\mathrm{u}$ isto vreme. $\mathrm{Da}$ bi to procenio, sudiji treba pomoć veštaka medicinske struke, jer sam to znanje ne poseduje [7].

\section{Opšti uslovi građanskopravne odgovornosti}

Opšti uslovi građanske odgovornosti zbog lekarske greške su: krivica lekara, šteta za pacijenta, uzročna veza između stručne greške i štete. ${ }^{4}$

Krivica lekara. Odgovornost zbog lekarske greške, moguća je i na osnovu ugovora i na osnovu delikta, ali uvek po principu krivice. Načelno, lekar odgovara samo u slučaju kad mu se njegova greška može upisati u krivicu [17]. Za razliku od krivične, građanska odgovornost lekara ne iziskuje težu krivicu, nego je dovoljna i obična nepažnja. Prilikom ocene krivice, ne vodi se računa o ličnim sposobnostima i znanju tuženog lekara, nego se sudija uvek pita, kako bi se na istom mestu tuženog ponašao iskusan i savestan lekar odgovorajuće struke, tj. bitna je pažnja "dobrog stručnjaka" [17] koja je viši stepen pažnje od "pažnje dobrog domaćina". Individualna neznanja ili slabosti, ne opravdavaju dotičnog lekara; ali ako on raspolaže neobično visokim znanjima i sposobnostima, dužan je da i njih upotrebi u korist pacijenta. Na taj način, se

\footnotetext{
${ }^{4}$ „Obaveza tužene da tužilji naknadi štetu postoji samo u slučaju postojanja lekarske greške, štete i uzročno-posledične veze između lekarske greške i nastale štete“, iz presude Vrhovnog kasacionog suda, Rev 1070/2018 od 05.06.2019. godine.
}

garantuje pacijentu, da se može osloniti na svoje verovanje da svaki lekar poseduje znanje i sposobnosti, koji su mu potrebni da bi svoje zanimanje obavljao, prema aktuelnom medicinskom standardu [18]. Kad lekar ne postupa s pažnjom dobrog stručnjaka, radi se o običnoj nepažnji (culpa levis), a ako ne postupa ni onako kako bi postupao svaki prosečan lekar radi se o gruboj nepažnji (culpa lata) koja predstavlja viši stepen krivice [15]. Prema tome, krivica se sastoji u pogrešnom postupanju. Za nekoga ćemo reći da je kriv, kada nije postupao onako kako je trebalo, a to znači kada njegovo ponašanje odstupa, od ponašanja koje se moglo osnovano očekivati od pažljivog i razumnog čoveka. To merilo se procenjuje prema pravilima struke, u skladu sa protokolima lečenja, pri čemu za postojanje odgovornosti nisu od značaja neke druge okolnosti, na primer pitanje da li lekar ima ili nema dovoljno znanja ili radnog iskustva (na primer, da se nalazi na specijalizaciji) i slično [19].

Utvrđivanje krivice sastoji se, dakle, iz dve faze: sud će najpre utvrditi kako se u konkretnom slučaju ponašalo lice čijom radnjom je prouzrokovana šteta, a zatim će u drugoj fazi to ponašanje uporediti sa ponašanjem koje se osnovano moglo očekivati od razumnog i pažljivog čoveka u takvoj situaciji. Za ovakvo shvatanje o krivici se kaže da ono predstavlja objektivizovano gledanje na krivicu (prosuđivanje krivice in abstracto) [20,21]. Kada se polazi od objektivnog standarda pažnje koji se smatra konstantom, misli se na onu koja se, prema nemačkom pravu, realno može očekivati od savesnog lekara istog ranga. Prema francuskom pravu, pažnja se može očekivati od dobrog stručnjaka, koji je u istoj kategoriji i u istom rangu, sa lekarom koji vrši procenu njegovog ponašanja. $U$ anglosaksonskom pravu, se ta procena vrši na osnovu ponašanja razumno kompetentnog lekara, čije se ponašanje i poštovanje dužne pažnje procenjuje [22].

Savremenija shvatanja medicinske i pravne nauke, idu u smeru da lekar čini namernu grešku (diskutabilno pitanje) prvo, zbog nedovoljne informisanosti o postojanju novih naučnih saznanja i o mogućnostima primene modernih tehnološkomedicinskih dostignuća, i/ili drugo, ukoliko je znao da navedena postoje, ali ih i pored postojećih uslova $u$ datom momentu nije svesno primenio. Lekar takođe pravi grešku, ukoliko ne shvati na vreme da je medicina kao retko koja druga nauka podložna drastičnim promenama, i da su moderna naučna saznanja njena svakodnevnica [23].

Medicinska sestra, iako najčešće nije u prvom planu kao odgovorna, nesporno može snositi odgovornost. To može biti zato jer nije provela odlukunaredbu ili nalog lekara (ili sebi nadređene sestre, na primer nije dala lek u određeno vreme), ali i iz 
drugih razloga, npr. zato što je propustila uočiti neki simptom krize kod bolesnika [24]. ${ }^{5}$

U parnicama najčeće su kao tuženi označeni sami štetnici, ili medicinske ustanove u kojima su zaposleni [17]. Ako su zajedno tuženi, imaju položaj tzv. prostih suparničara, s tim što ustanova, pod određenim uslovima, ima pravo da se regresira od štetnika [16].

Šteta za pacijenta. Zakon definiše da je posledica stručne greške povreda, oštećenje, pogoršanje zdravlja, ili gubitak delova tela pacijenta. Uopšteno šteta uslovljena lekarskom greškom, može biti materijalna i nematerijalna, i za tu podelu važe opšta pravila o odgovornosti za štetu. Vidovi nematerijalne štete propisani su čl. 200. Zakona o obligacionim odnosima (pretrpljeni fizički bolovi, pretrpljeni duševni bolovi zbog umanjenja životne aktivnosti, naruženosti, povrede ugleda, časti, slobode ili prava ličnosti, smrti bliskog lica kao i pretrpljen strah) a materijalna šteta se najčešće ogleda, u manje isplaćenoj zaradi za vreme bolovanja, troškovima lečenja i nabavke medicinskih sredstava i pomagala, a u slučaju smrti ili teškog invaliditeta i u izgubljenom izdržavanju i trajnom umanjenju zarade. Postoje i parnice u kojima se traži naknada materijalne štete, zbog izgubljene šanse za napredovanje u karijeri [16]. Posledica stručne greške se može sastojati u nastupanju smrti, u pogoršanju već postojeće bolesti, ili u izazivanju oboljenja u zdravog lica. Sem toga, pogoršanje zdravlja može biti izraženo u nepotrebnom ili neočekivanom trpljenju bolova, u smanjenju mogućnosti uspeha lečenja, ili u produženom vremenu za ozdravljenje. Ako usled stručne greške izostane uspeh lečenja, u tome već treba videti oštećenje zdravlja, pod uslovom da je pacijent zbog toga izložen patnji koja se mogla izbeći. To važi osobito kad je potreban novi zahvat, da bi se postigao cilj lečenja, ili kad je stanje tela pacijentovog uobličeno drugačije nego što je on hteo [1]. $S$ druge strane, stručna greška može usloviti izvesne specifične oblike štete, kao što je, na primer, tzv. prenatalna šteta $\mathrm{i}$ šteta zbog povrede prava na planiranje porodice. Ova druga, ispoljava se u šteti zbog neželjenog rođenja, zdravog ili teško oštećenog deteta. Pravo na naknadu tog oblika štete, priznato je u sudskoj praksi izvesnih evropskih zemalja i SAD, a u novije vreme nadoknada ove štete uređuje se i posebnim zakonima [18].

Uzročna veza između lekarske greške $i$ štete Odgovornost zbog lekarske greške pretpostavlja uzročnu vezu između greške i štete. Pitanje uzročne veze je, zapravo, jedno od centralnih i najtežih pitanja, koja se tiču odgovornosti lekara prema pacijentu, jer je u prirodi čoveka da umre. Teško je dokazati da štete koju je podneo bolesnik, ne bi bilo da nije načinjena lekarska greška. Uprkos teškoćama i nesigurnostima, sudija se ne može odreći utvrđivanja uzročne veze između greške i štete. On je dužan da postojanje uzročne veze prihvati ili odbaci, zavisno od uverenja koje je o tome stekao.

\footnotetext{
${ }^{5}$ Interesantno je rešenje u Hrvatskom pravu prema kojem medicinske sestre čini na određeni način manje odgovornim. Odredbom člana 21. Zakona o sestrinstvu Republike Hrvatske, Narodne novine RH, br. 121/03, 117/08, 57/11 propisano je ,Medicinska sestra nije odgovorna za neprovedeni postupak u slučaju kada unatoč primjeni najboljeg znanja i vještina, poslodavac nije osigurao ordinirane lijekove, sredstva, minimalno potrebni pribor ili tehničku opremu u skladu $\mathrm{s}$ minimalnim standardima za provođenje uspješne zdravstvene njege".
}

No, budući da se to uverenje zasniva na mišljenju medicinskih veštaka ${ }^{6}$ ili u sprovedenom nadzoru, ${ }^{7}$ ono nije matematičko i ne isključuje svaku suprotnu mogućnost. Sudija se zato mora zadovoljiti pretežnom verovatnoćom da uzročna veza postoji ili ne postoji. Uzročna veza smatra se utvrđenom ako pacijent dokaže da je lekar načinio grešku i da takva greška, prema saznanjima medicinske nauke i lekarskog iskustva, vodi tipično ka šteti koja je nastala. ${ }^{8}$ Tada je stvar lekara da dokaže, da se u konkretnom slučaju taj tipičan kauzalni razvoj nije ostvario, nego da je reč o atipičnom ishodu. Ako su prekršena priznata pravila lekarske veštine, tada po pravilu, postoji verovatnoća da je greška uzrok štete po pacijenta. Dovoljan je, dakle, visok stepen verovatnoće, umesto apsolutnog dokaza, a u slučaju nužde dovoljna je i puka indicija [1]. Lekarska greška treba da bude conditio sine qua non nastaloj šteti. Ukoliko bez lekarske greške šteta ne bi nastupila, možemo reći da je postojao odnos uzročnosti između njih, i da je greška lekara za direktnu posledicu imala datu štetu. Ako bi pak šteta svakako nastupila, nevezano za pogrešno postupanje lekara, tada se ne može govoriti o postojanju uzročnosti [25]. Lekar odgovara jedino zbog štete koju bi propisnim postupanjem mogao izbeći; nema odgovornosti zbog neizbežnih šteta [18].

\section{Teret dokazivanja}

Zakon o parničnom postupku [26] uvodi načelo dispozicije stranaka, poznato i kao načelo formalne istine, koje podrazumeva da samo stranke u postupku mogu predlagati dokaze, ${ }^{9}$ dok se uloga suda ograničava na odluku da li će usvojiti neki dokazni predlog ili ga odbiti, a nije ovlašćen da sam određuje dokaze mimo predloga stranaka, sem u izuzetnim slučajevima.

\footnotetext{
6،Bez razjašnjenja postojanja lekarske greške i uzročno-posledčne veze između lekarske greške i nastale štete ne može se prihvatiti zaključak o odgovornosti tuženog za lekarsku grešku. Radi utvrđenja ove činjenice potrebno je stručno znanje kojim sud ne raspolaže to je tu činjenicu bilo potrebno utvrditi na osnovu izvedenog dokaza veštačenjem od strane Sudkomedicinskog odbora...", iz presude Vrhovnog kasacionog suda, Rev 1070/2018 od 05.06.2019. godine.

7"'Sud je utvrdio da je tuženi Klinički centar odgovoran shodno čl. 170. i 171. u vezi sa čl. 18. ZOO i čl. 197. Zakona o zdravstvenoj zaštiti jer radnici tuženog nisu pružili pažnju dobrog stučnjaka i nisu radili u skladu sa vežećim medicinskim standardom, a što je inače utvrđeno u vanrednom nadzoru nad stručnim radom Urgentnog centra, Instituta za ginekologiju i akušerstvo, Instituta za neuropsihijatrijske bolesti, kao i Instituta za infektivne i tropske bolesti KC od 7. 11. 2002. godine i rešenja koje je donelo Ministarstvo zdravlja", iz presude Prvog osnovnog suda u Beogradu, P. br. 6971/11. od 11. 10. 2011. godine koja je potvrđena presudom Apelacionog suda u Beogradu Gž. br. $3813 / 12$

${ }^{8}$, ,Revizijski sud smatra da je tužena odgovorna za štetu koju tužilac trpi, obzirom da između radnje tužene - pružanje stručne lekarske pomoći i zdravstvenog stanja do koga je usled toga došlo kod tužioca, postoji uzročnoposledična veza. Tužena je odgovorna jer je u lečenju primenila metodu koja više nije priznata od strane zvanične medicine...", iz presude Vrhovnog kasacionog suda, Rev 1296/10 od 23.09.2020. godine.

9،..nije utvrđena uzročno-posledična veza između navedene operacije koju je izvršila tužena i štete nastale u vezi sa tim na strani tužioca, jer tužilac nije predložio sudsko-medicinsko veštačenje na ovu okolnost. Osim toga, tužilac nije ni dokazao da je pretrpeo vidove štete za koje traži naknadu, što je opet jedino moglo biti utvrđeno stručnim nalazom i mišljenjem veštaka koje takođe nije izvršeno, a na tužiocu je teret dokazivanja shodno odredbi čl. 223. ZPP”, iz presude Apelacionog Suda u Beogradu Gž. br. 8848/10. od 22.5.2013. godine.
} 
Pravila o teretu dokazivanja umnogome utiču na uspeh stranke u sporu jer, zavisno od vrste lekarske greške, teret dokazivanja leži na različitim učesnicima parničnog postupka, tužiocu ili tuženom, koji se izlažu opasnosti gubitka spora, u slučaju da nisu u stanju da dokažu postojanje neke od odlučnih činjenica na kojima baziraju svoj zahtev. ${ }^{10}$

Sudovi su stanovišta da teret dokazivanja lekarske greške $u$ užem smislu, tj. činjenice da je šteta za tužioca nastala postupanjem medicinskog radnika protivno pravilima struke, postojanja štete, te uzročnoposledične veze između radnje lekara i štete, kao i teret dokazivanja uzročno-posledične veze između nepostojanja informisanog pristanka i štete, na tužiocu. Teret dokazivanja lekarske greške, odnosno uzročnoposledične veze između pogoršanja zdravstvenog stanja, $i$ dijagnoze $i$ terapije koju je zdravstvena ustanova odredila, je na pacijentu, odnosno onome ko tvrdi, da je zbog lekarske greške došlo do navedene štete [27]. Samo teret dokazivanja postojanja informacije, i pristanka pacijenta o planiranoj meri, odnosno poštovanja pacijentovog prava na obaveštenje, pada na tužene, što njih (pacijente) dovodi u mnogo lakši procesni položaj [16]. Međutim, lekar snosi teret dokazivanja da šteta nije posledica njegove greške, u onom slučaju kada se utvrdi, da je lekarska greška gruba, i da je pacijent pretrpeo štetu koju je propisno postupanje lekara trebalo da spreči [28]. Radi se o tome da u ovom slučaju postoji pretpostavka uzročnosti, koju lekar mora oboriti ukoliko želi da se oslobodi od odgovornosti za štetu. Teret dokazivanja nepostojanja uzročne veze, prebacuje se na zdravstvenog radnika, uvek kada postoji velika verovatnoća da je gruba lekarska greška jedini uzrok štete, odnosno ukoliko nisu izuzetno male šanse, da je gruba lekarska greška uzrok štete [29].

Objektivna odgovornost zdravstvenih radnika (bez obzira na krivicu) moguća je samo izuzetno, tj. samo u zakonom predviđenim slučajevima. Jedan od takvih slučajeva je i šteta prouzrokovana pacijentima koji učestvuju u medicinskim ogledima. Za takve štete, koje pretrpe na svom telu ili zdravlju, pacijenti imaju pravo na naknadu, "u skladu sa zakonom, bez obzira na krivicu". ${ }^{11}$

Posebno značajno je postojanje objektivne odgovornosti zbog štete nastale upotrebom medicinskih sredstava. Pravilo da šteta nastala u vezi sa opasnom stvari, odnosno opasnom delatnošću potiče od

\footnotetext{
10 "Veštačenjem je utvrđena uzročno-posledična veza, odnosno da je oštećenje nerva upravo u uzročnoposledičnoj vezi sa delovanjem medicinskog osoblja koje je izvodilo hirurški zahvat (tzv. lekarska greška), te je teret dokazivanja suprotnog, odnosno preduzimanja svih potrebnih mera radi prevencije i smanjenja rizika moguće štete, prešao na zdravstvenu ustanovu", iz presude Apelacionog suda u Novom Sadu, Gž 2216/2013 od 20.06.2013. godine.

${ }^{11}$ Zakon o pravima pacijenata, čl. 25. st. 8.: „Pacijent, koji zbog medicinskog istraživanja pretrpi štetu na svom telu ili zdravlju, ima pravo na naknadu štete u skladu sa zakonom, bez obzira na krivicu”.
}

te stvari, odnosno delatnosti, izuzev ako se dokaže da one nisu bile uzrok štete [17]. Stoga, ukoliko je šteta pričinjena upotrebom medicinskog sredstva koje se može podvesti pod pojam opasne stvari, ili primenom određene dijagnostičke ili terapijske mere koja bi se mogla podvesti pod pojam opasne delatnosti, zadatak pacijenta je samo da dokaže da je šteta nastala u vezi sa medicinskim sredstvom, odnosno dijagnostičkom ili terapijskom merom [30]. Lekar mora dokazati, da šteta nije posledica upotrebe opasne stvari, ili obavljanja opasne delatnosti, ukoliko se želi osloboditi odgovornosti za štetu koja je pričinjena pacijentu.

\section{Zaključak}

Uopšteno, pod lekarskom greškom se podrazumeva svaka mera lekar, koja nije u skladu sa dobrom lekarskom praksom, odnosno aktuelnim medicinskim standardom. koji su uglavnom sadržani u vodičima dobre kliničke prakse, i protokolima lečenja. Vodiči dobre kliničke prakse i protokoli su ustanovljeni, kao putokaz lekarima i medicinskim ustanovama, kroz redosled radnji i metoda koje treba preduzeti i primeniti prilikom zbrinjavanja pacijenta sa određenim zdravstvenim problemom.

Opšti uslovi građanske odgovornosti zbog lekarske greške su: krivica lekara, šteta za pacijenta, uzročna veza između stručne greške i štete. Krivica se sastoji u pogrešnom postupanju s tim što građanska odgovornost lekara ne iziskuje težu krivicu, nego je dovoljna i obična nepažnja. Prilikom ocene krivice bitna je pažnja "dobrog stručnjaka".

Posledica stručne greške je povreda, oštećenje, pogoršanje zdravlja ili gubitak delova tela pacijenta, a šteta može biti materijalna i nematerijalna. Stručna greška može usloviti izvesne specifične oblike štete, kao što je, na primer, tzv. prenatalna šteta i šteta zbog povrede prava na planiranje.

Teret dokazivanja lekarske greške, odnosno uzročno-posledične veze između pogoršanja zdravstvenog stanja i dijagnoze i terapije koju je lekar odredio, je na pacijentu, odnosno onome ko tvrdi da je zbog lekarske greške došlo do navedene štete. Međutim, lekar snosi teret dokazivanja, da šteta nije posledica njegove greške, $u$ onom slučaju kada se utvrdi da je lekarska greška gruba, i da je pacijent pretrpeo štetu koju je propisno postupanje lekara trebalo da spreči.

Sukob interesa: autor izjavljuje da nema sukob interesa. 


\section{Literatura}

1. Radišić J. Građanska odgovornost lekara koja proističe iz njihovog zanimanja. Revija za pravo osiguranja. 2009; 7(1):11-27.

2. Nikolić Đ. Pravna priroda građanskopravne odgovornosti medicinskih poslenika. Zbornik radova Pravnog fakulteta u Nišu. 2017; 56(76):447-465.

3. Marković V. Individualni preduzetnik - pravni okvir poslovanja. Beograd: Poslovni biro. 2016.

4. Marković V. Vićentijević K. Petrović Z. Term and Legal Position of an Individual Entrepreneur in Republic of Serbia. Moskow: Russian Journal of Legal Studies. 2017; 4(4): 20-33.

5. Dabić Lj. Građanskopravna odgovornost nosilaca slobodnih profesija. Beograd. Vox iuris. 2009.

6. Marković, V. Odgovornost advokata iz ugovora o punomoćstvu. U: Mićović M (ur): Usluge i zaštita korisnika. Kragujevac: Pravni fakultet. 2015.

7. Simić J. Lekarska greška - građanska odgovornost zbog lekarske greške. Beograd: Službeni glasnik. 2018.

8. Božoć M. Povreda prava osobnosti - ugovorna i izvanugovorna odgovornost, završni rad. Požega: Veleučilište u Požegi, 2017.

9. Nakić J, Belanić L. Sličnosti i razlike naknade štete nastale pacijentima u zdravstvenoj ustanovi u Republici Sloveniji i Republici Hrvatskoj (kroz dva sudska predmeta). Zbornik Pravnog fakulteta Sveučilišta u Rijeci. 2019, 40 (1): 445-479.

Mujović-Zornić H. Pravna priroda lekarske odgovornosti za štetu. Strani pravni život. 1999; (12): 111 .

10.Zakon o pravima pacijenata. Sl. glasnik RS, br. 45/2013 i 25/2019 - dr. zakon, čl. 31.

11.Marković, V. Uvod u zdravstveno pravo. Beograd; Univerzitet Singidunum. 2021.

12.Zakon o zdravstvenoj zaštiti. Sl. glasnik RS, br. 25/2019, čl. 186.

13.Komora medicinskih sestara i zdravstvenih tehničara Srbije. Pravilnik o pružanju pomoći članovima Komore u slučaju učinjene stručne greške, 2015. Dostupno na:

http://www.kmszts.org.rs/akti/PravilnikStru\%C4\%8

DnaGre\%C5\%A1ka2016.pdf

14.Radišić J. Pojam lekarske greške. Pravni život. 2010; 539(9):181-195.

15.Smailović S. Obligaciono pravo II skripta - Babić I, $2020 . \quad$ Dostupno na: https://www.academia.edu/43331175/obligaciono_p ravo_ii_skripta_Ilija_Babi\%C4\%87

16. Marčetić D, Filipović V. Parnice iz medicinskog prava. Glasnik advokatske komore Vojvodine. 2020; 92(1):95-110.DOI: https://doi.org/10.5937/gakv9226329

17.Zakon o obligacionim odnosima. Sl. list SFRJ, br. 29/78, 39/85, 45/89 - odluka USJ i 57/89, Sl. list
SRJ, br. 31/93, Sl. list SCG, br. 1/2003 - Ustavna povelja i Sl. glasnik RS, br. 18/2020: čl. 154; čl. 18. st. 2 ; čl. 170. i 171; čl. 173.

18.Radišić J. Medicinsko pravo. Beograd: Pravni fakultet Univerziteta Union i JP Službeni glasnik. 2008.

19.Počuča M, Šarkić N, Mrvić-Petrović N. Lekar-ska greška kao razlog pravne odgovornosti lekara i zdravstvenih ustanova. Vojnosanitetski pregled. 2013; 70(2):207-214. DOI: 10.2298/VSP1302207P.

20. Orlić M. Građansko-pravna odgovornost advokata u srpskom pravu. Beograd: Intermeks. 2006.

21. Marković, V. Ugovor o punomoćstvu. Glasnik advokatske komore Vojvodine. 2012; 84(12):790820.

22.Deutsch E. Medizinrecht: Arztrecht, Arzneimittelrecht und Medizinprodukterecht, Berlin, Heidelberg: Springer. 1997, p.185.

23.Totić M. Pravno shvatanje namerne lekarske greške. Medicinski glasnik. 2017; 22(64):33-46.

24.Ivančić-Kačer B. Odgovornost za štetu drugih osoba osim liječnika u zdravstvu., U: Mićović M (ur): XXI vek - vek usluga i Uslužnog prava. Kragujevac: Pravni fakultet. 2011, p.317.

25.Radovanov A, Stefanović N. Naknada štete pacijentu usled lekarske greške. U: Petrović Z (ur): Odgovornost za štetu, naknada štete i osiguranje, Beograd - Valjevo. 2018: p.147.

26.Zakon o parničnom postupku. Sl. glasnik RS, br. $72 / 2011 \ldots 18 / 20$.

27.Aleksić N. Lekarska greška, odgovornost zdravstvene ustanove i prava pacijenata u sudskoj praksi - sa osvrtom na odgovornost države u praksi Evropskog suda za ljudska pava. Pravni portal. 2020. Dostupno na: https://www.pravniportal.com/ lekarska-greska-odgovornost-zdravstvene-ustanovei-prava-pacijenta-u-sudskoj-praksi-sa-osvrtom-naodgovornost-drzave-u-praksi-evropskog-suda-zaljudska-prava/

28. Radišić J. Uzročna veza kao osnov i kao mera odgovornosti zbog lekarske stručne greške. Pravni život. 1998; 47(9):239-252.

29. Manić S. Uzročna veza kao uslov odgovornosti medicinskih poslenika. Zbornik radova Pravnog fakulteta u Nišu. 2019; 58(84):209-226.

30.Manić S. Odgovornost zbog štete izazvane upotrebom medicinskih sredstava. Zbornik radova Pravnog fakulteta Novi Sad. 2019; 53(2): 561-572. 
REVIEW ARTICLE

\title{
CIVIL LIABILITY FOR DOCTORS IN THE FACE OF A PROFESSIONAL (MEDICAL) ERROR
}

\author{
Velisav MARKOVIĆ
}

Faculty of Health and Business Studies, University SINGIDUNUM Belgrade, Serbia

\begin{abstract}
Civil liability for healthcare workers and healthcare institutions is one of the most significant problems in Health and Medical Law. The basis of responsibility is always an open question, whether it be medical errors, misinformation or faulty work organization. Aiming to make things clearer for individuals practising medicine, this paper presents the concept of a professional (medical) error, the basis of responsibility for the doctor (medical error, damage to the patient and the cause-and-effect relationship between a medical error and the damage caused) as well as the precise explanation of who has to prove what in possible court proceedings.
\end{abstract}

Keywords: professional error, medical error, civil liability, healthcare worker 